\title{
Drug Delirium Scale (DDS): A Tool to Evaluate Drugs as a Risk Factor for Delirium
}

\author{
Nguyen, Patrick Viet-Quoc, B.Pharm, M.Sc. ${ }^{1,2}$ Pelletier, Lucie, B.Pharm, M.Sc. ${ }^{1}$, Payot, Isabelle, M.D. , \\ Latour, Judith, M.D. ${ }^{1}$ \\ ${ }^{1}$ Montreal University Hospital Centers (CHUM), \\ 1058 St-Denis, Montreal, H2X3J4 Canada \\ ${ }^{2}$ CHUM Research Center,
}

Tour viger, Pavillion R, 221, 900 Saint Denis Street, Montreal H2X0A9, Canada

Corresponding author - Nguyen, Patrick Viet-Quoc

242 Rue de Lorraine, Saint-Lambert, Quebec, J4S 1T1, Canada

\section{Structured Abstract (201 words)}

Objectives: To design the Drug Delirium Scale (DDS), an evaluation tool to assess the drug burden in delirium in the elderly population.

Design: We proceeded with a systematic literature review through database and grey literature. The records were examined by two independent reviewers using the inclusion and exclusion criteria. Data from the selected studies was extracted and a summary chart was written for each drug. Drugs in anticholinergic drug scales, Beers and STOPP criteria for anticholinergic of cognitive impairment effects were also included for evaluation. These summaries were submitted to the geriatric expert panel composed of two geriatric physicians and two geriatric pharmacists. The panel chose each drug included in the DDS list and their rank.

Results: 981 records were identified and 149 met inclusion criteria. The expert panel evaluated 265 drugs and selected 96 drugs for the DDS scale. The mean interrater reliability score was of 0,634 [CI: 0,441; 0,791].

Conclusion: The Delirium Drug Scale (DDS) is the first evaluation tool to assess the risk of delirium derived from drugs used in the elderly population. It was designed using a sound methodological process. The DDS must now be tested in the geriatric population to validate its predictive value for delirium.

Keywords: Delirium, Aged, Risk Assessment, Cholinergic Antagonists.

\section{Introduction}

Delirium is a clinical syndrome of sudden onset where the person's cognitive and perceptual functions are impaired. Consciousness and attention are altered and fluctuate during the day. Delirium affects the elderly population in a larger proportion especially in the presence of dementia, severe illness, and long hospital stay.[1] Prevalence of medical in-patient delirium ranges from 10 to $31 \%$.[2] Patients affected by delirium during a hospital stay have an increased risk of functional loss, cognitive impairment, and mortality. Delirium also has been associated with a longer hospital stay and institutionalization. [2] Delirium is usually related to an underlying pathophysiological cause. Infection, head trauma, cerebrovascular and metabolic diseases are known causes of delirium. Drugs are also a common cause of delirium, among them anticholinergic drugs.[3, 4]

The goal of the current study is to design a delirium specific drug evaluation tool for the elderly population using a systematic review of medical literature and a consensus panel of geriatric professionals.

\section{Methods}

The Delirium Drug Scale (DDS) is an evaluation tool to assess the drug burden in delirium in the elderly 


\section{International Journal of Innovative Research in Medical Sciences (IJIRMS) \\ ISSN (Online): 2455-8737, Vol. 01, Issue 06, August 2016 \\ Available online at $-w w w . i j i r m s . i n$}

population. A rank of 1 or 2 is attributed to each member of the DDS drug list. To calculate the DDS score, the patient's medication list is compared to the DDS. The rank attributed to the drug is multiplied by the dosage factor to give the weighted rank. The dosage factor is the result of the administered daily dose taken divided by the sum of the administered daily dose and the minimal daily geriatric dose. (Figure 1) The DDS score is the sum of all weighted rank present in the patient's drug list. The dosage used for minimal daily dose proceeds from the Geriatric Dosage Handbook.[5]

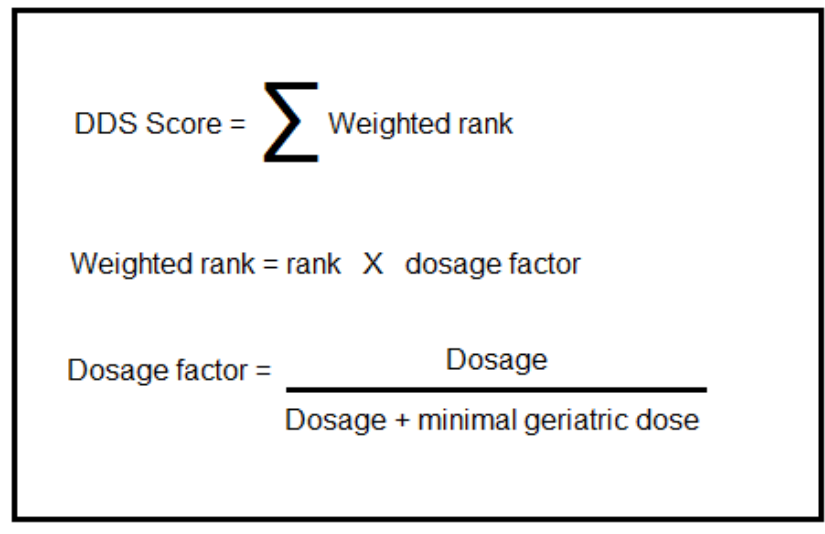

Figure 1: DDS score

We proceeded with a systematic literature review in the Medline [1946 to 2013], PubMed [1964 to 2013], and Embase [1974 to 2013] database. The following keywords were used : Cholinergic antagonist OR Anticholinergic OR Cholinergic receptor blocking agent OR Muscarinic antagonist OR Muscarinic receptor blocking agent OR Drug AND Aged OR elderly OR old OR late life OR older AND Delirium OR Confusion OR acute confusional state OR disorientation OR acute confusion. (Search strategy in appendix 1) A grey literature search was also performed using reverse snowballing method.

The search results were examined for duplicate records which were removed. Article's title, and abstract when available, was examined by two independent reviewers using the following inclusion criteria: the publications are clinical trials, epidemiological studies, case reports or meta-analysis, the publication concerned a drug currently available in Canada and the publication evaluated the association of drugs with delirium. Articles written a language other than English or French, reviews, systematic reviews and guidelines were excluded. Studies on drugs unavailable or discontinued in Canada were also removed. Studies where full text and abstract were unavailable were excluded.

The following data was extracted from the selected studies full text or abstract: study design; the number of subjects; age (mean or range); characteristics of the study population; drug; AHFS class; intervention; the comparator; association with delirium. Once the data was extracted, a summary chart was elaborated for every drug included in the selected studies. The drugs in the Anticholinergic Risk Scale (ARS), Anticholinergic Drug Scale (ADS), and Cognitive burden scale (ACB), Beers and STOPP criteria for anticholinergic, cognitive impairment or cognitive decline were also included for evaluation. All pharmacodynamics data were added to the summary chart for each drug when available in drug monograph. No standardized quality assessment of studies was conducted.

These summaries were submitted to the geriatric expert panel composed of two geriatric physicians and two geriatric pharmacists. With the submitted data, each member of the panel decided to include or exclude the drug from the list. They also indicated the association strength of 1 or 2 for each included drug. The drug was excluded from the scale if it had no anticholinergic property or no central nervous system (CNS) penetration and no association with delirium. The included drugs were ranked 1 if they had low anticholinergic properties and low central nervous system penetration, low anticholinergic properties and affinity to the CNS muscarinic receptors or weak association with delirium in published studies. Drugs with high anticholinergic properties and CNS penetration, high anticholinergic properties and affinity to the CNS muscarinic receptors or strong association with delirium were ranked 2 .

Finally, the members of the panel met to compare and decide which drug to include in the DDS list and the rank attributed to each drug.

Statistical analysis: A Krippendorff's kappa will be calculated to evaluate interrater reliability in the expert panel.[6] 


\section{International Journal of Innovative Research in Medical Sciences (IJIRMS) \\ ISSN (Online): 2455-8737, Vol. 01, Issue 06, August 2016 \\ Available online at $-\underline{w w w . j j i r m s . i n}$}

\section{Result}
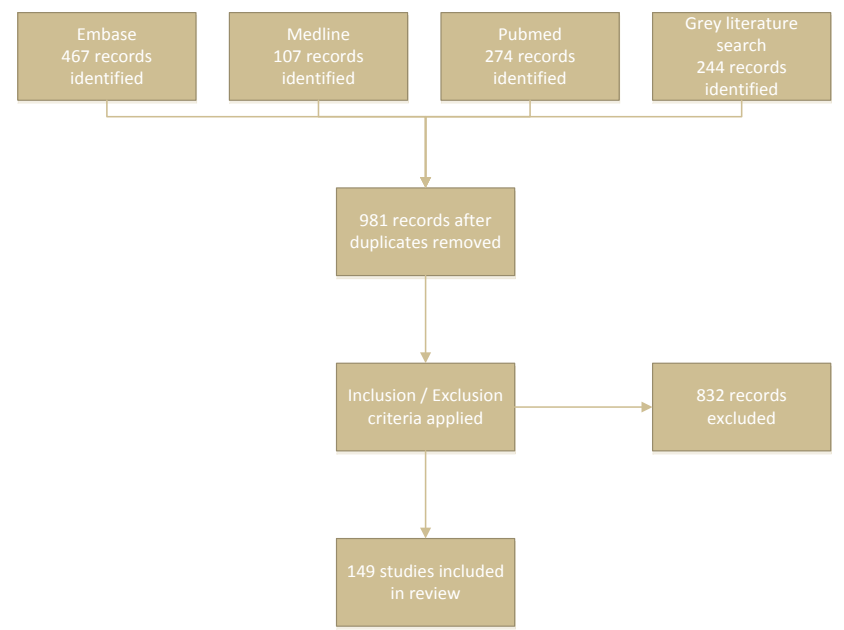

\section{Figure 2: Flow information of systematic review}

With the initial search strategy, 821 records were identified, 467 in Embase, 107 in Medline and 247 in Pubmed database. The grey literature search found 244 records. (Figure 2) There were 119 duplicate records and 149 met inclusion criteria. There were 6 randomized and 1 none randomized controlled clinical trials, 7 prospective and 5 retrospective cohort studies, 2 retrospective case-control studies, 25 case series and 103 case reports. This studies included a total of 264 012 participants as reported in table 1 .

\begin{tabular}{|c|c|}
\hline Clinical trials & 663 \\
\hline Cohort studies & 262728 \\
\hline Case-control studies & 159 \\
\hline Case series & 355 \\
\hline Case report & 107 \\
\hline
\end{tabular}

The expert panel evaluated 265 drugs and selected 96 drugs for the DDS listed in table 2. The mean interrater reliability score was of 0,634 [CI: 0,$441 ; 0,791]$.

\section{Discussion}

Many scales developed to assess the anticholinergic drug burden have been used to evaluate the risk of delirium attributed to drugs.[7-9] The Anticholinergic Drug Scale (ADS) rates drug in a 0 to 3 scale where 0 is equivalent to none and 3 the highest anticholinergic activity.[10] The drugs were evaluated by assessing their in vitro affinity to muscarinic receptors compared to that of atropine. The strength of this scale is the valid, standardized and reproducible evaluation of anticholinergic properties. On the other hand, this anticholinergic affinity is pure and doesn't take into account the pharmacodynamics properties of drugs such as CNS penetration. Therefore, some drugs could have only peripheral anticholinergic effects which make ADS less specific to delirium. Finally, it difficult to keep the list updated as new drugs enter the market and aren't systematically tested for their anticholinergic properties.

The Anticholinergic Risk Scale (ARS) was designed to evaluate the anticholinergic burden leading to cognitive impairment and delirium. [11] The 500 most prescribed drugs in the Veterans affairs Boston Healthcare System were also ranked from 0 to 3 according to their anticholinergic activity by a geriatrician and to geropharmacists. Various sources such as the KiBank database for cholinergic receptor dissociation constant, Micromedex database and MEDLINE search were used to rank the medication. The specific evaluation and database search strategy wasn't specified. It is also difficult to extrapolate the list since it was developed in a predominantly masculine geriatric population while general geriatric care population is mixed and with mostly of a feminine predominance.

The Cognitive burden scale (ACB) is based on a similar methodology to this study.[12] The aim was the development of a list of anticholinergic drugs with a negative impact on cognitive function. Delirium was included in the negative effects as was dementia, mild cognitive impairment, and cognitive decline. The specific methodology on the keywords, results of the systematic review and data extraction were not specified. The list was not specifically designed for delirium.

The drug burden index (DBI) takes into account anticholinergic and sedative property of drugs as well as drug dosage.[13] The content of the list as well as methodological design wasn't published which renders analysis and comparison difficult.

Even if some of these scales have been tested for their association to delirium, they have not been specifically 


\section{International Journal of Innovative Research in Medical Sciences (IJIRMS) \\ ISSN (Online): 2455-8737, Vol. 01, Issue 06, August 2016 \\ Available online at $-\underline{w w}$. ijirms.in}

designed to this purpose.[8, 14, 15] Hence, they only take into account the anticholinergic and in the case of DBI sedative property of drugs while other neurotransmitters such as dopamine, serotonin or GABA and cytokines have been associated to delirium.[16, 17] Theses scales may therefore come short in detecting drugs putting patients at risk of delirium.

The DDS has a specific purpose, the elaboration of a risk score from a drug list putting elderly patients at risk of delirium. To achieve its goal, a specific methodology was elaborated using independent reviewers for article selection. This methodology details the information taken into account in the elaboration process. Finally, the interrater reliability test reveals a substantial agreement in the expert panel.[18] The sound methodology allows this scale to apply to the general geriatric population. The DDS doesn't only take in account the anticholinergic effect but all drug effect on the central nervous system (CNS) leading to delirium. It also takes into account geriatric drug dosage in the risk score rendering it more sensible to the effect of drug dosage variation on the CNS.

The DDS is based on literature review and the evaluation of geriatric practitioner. There are limits to the current study. Publications, especially prior to 1980, were sometimes unavailable so the abstract was used. Most of the data used in the elaboration of this scale proceeded from observational studies and case reports. It was therefore difficult to evaluate the causality link between the drug and delirium due to confounding variables and methodological impairments. The drugs included had to be available in Canada which may limit the capacity to generalize the tool to other countries. It will be necessary to validate the tool in different worldwide location to ensure its applicability. Even if the agreement among the members of the panel was substantial, differences were still present. This can be explained by the use of different background knowledge and experience in the interpretation of the extracted data. Since new medications are regularly available to patients and others are discontinued, the DDS must be frequently updated to the new information published on current and future drugs.

\section{Conclusion}

The DDS is the first scale designed to evaluate delirium drug burden. It is the result of a systematic review of literature coupled with expert evaluation. In order to be valid, the DDS must be tested in many clinical contexts in order to validate its predictive value on delirium.

\section{Acknowledgments}

We would also like to show our gratitude to Konan Jacques Kouamé, Éliane Duong and Clément Wai for their contribution in the extraction of data for the systematic review.

\section{Funding Source: None}

Conflict of Interest Checklist: None to declare

\begin{tabular}{|c|c|c|c|c|c|}
\hline Drug & Rank & Geriatric dose/day & Drug & Rank & Geriatric dose/day \\
\hline Acyclovir & 1 & $1000 \mathrm{mg}$ & Lithium & 1 & $600 \mathrm{mg}$ \\
\hline Alprazolam & 1 & $0.5 \mathrm{mg}$ & Lorazepam & 1 & $1 \mathrm{mg}$ \\
\hline Amantadine & 1 & $200 \mathrm{mg}$ & Loxapine & 1 & $20 \mathrm{mg}$ \\
\hline Amitriptyline & 2 & $10 \mathrm{mg}$ & Meperidine & 2 & $200 \mathrm{mg}$ \\
\hline Amphotericin & 1 & $0.3 \mathrm{mg} / \mathrm{kg}$ & Methocarbamol & 1 & $6 \mathrm{mg}$ \\
\hline Atropine & 2 & $0.5 \mathrm{mg}$ & Methylprednisolone & 1 & $40 \mathrm{mg}$ \\
\hline Baclofen & 2 & $10 \mathrm{mg}$ & Midazolam & 1 & $5 \mathrm{mg}$ \\
\hline Benztropine & 2 & $1 \mathrm{mg}$ & Mirtazapine & 1 & $7.5 \mathrm{mg}$ \\
\hline Bromazepam & 1 & $3 \mathrm{mg}$ & Moclobemide & 1 & $300 \mathrm{mg}$ \\
\hline Buprenorphine & 1 & $5 \mathrm{mcg} / \mathrm{hr}$ & Morphine & 1 & $20 \mathrm{mg}$ \\
\hline Bupropion & 1 & $100 \mathrm{mg}$ & Nitrazepam & 1 & $2.5 \mathrm{mg}$ \\
\hline Chlordiazepoxide & 2 & $10 \mathrm{mg}$ & Nortriptyline & 2 & $30 \mathrm{mg}$ \\
\hline Chlorpheniramine & 1 & $4 \mathrm{mg}$ & Olanzapine & 1 & $5 \mathrm{mg}$ \\
\hline Chlorpromazine & 1 & $10 \mathrm{mg}$ & Orphenadrine & 1 & $200 \mathrm{mg}$ \\
\hline Cimetidine & 1 & $800 \mathrm{mg}$ & Oxazepam & 1 & $10 \mathrm{mg}$ \\
\hline Citalopram & 1 & $10 \mathrm{mg}$ & Oxcarbazepine & 1 & $300 \mathrm{mg}$ \\
\hline Clinidium & 1 & $7.5 \mathrm{mg}$ & Oxybutynine & 2 & $7.5 \mathrm{mg}$ \\
\hline
\end{tabular}




\begin{tabular}{|c|c|c|c|c|c|}
\hline Clomipramine & 2 & $25 \mathrm{mg}$ & Oxycodone & 1 & $20 \mathrm{mg}$ \\
\hline Clonazepam & 1 & $0,5 \mathrm{mg}$ & Paroxetine & 1 & $10 \mathrm{mg}$ \\
\hline Clonidine & 1 & $0.1 \mathrm{mg}$ & Perphenazine & 1 & $12 \mathrm{mg}$ \\
\hline Clorazepate & 1 & $7,5 \mathrm{mg}$ & Phenelzine & 1 & $7.5 \mathrm{mg}$ \\
\hline Codeine & 1 & $60 \mathrm{mg}$ & Phenobarbital & 1 & $30 \mathrm{mg}$ \\
\hline Cortisone & 1 & $25 \mathrm{mg}$ & Phrochlorperazine & 1 & $10 \mathrm{mg}$ \\
\hline Cyclobenzaprine & 2 & $5 \mathrm{mg}$ & Pimozide & 1 & $1 \mathrm{mg}$ \\
\hline Cyproheptadine & 1 & $4 \mathrm{mg}$ & Pramipexole & 1 & $0.375 \mathrm{mg}$ \\
\hline Darifenacin & 1 & $7.5 \mathrm{mg}$ & Prednisone & 1 & $5 \mathrm{mg}$ \\
\hline Desipramine & 2 & $10 \mathrm{mg}$ & Pregabaline & 1 & $150 \mathrm{mg}$ \\
\hline Desvenlafaxine & 1 & $50 \mathrm{mg}$ & Procyclidine & 2 & $2.5 \mathrm{mg}$ \\
\hline Dexamethasone & 1 & $4 \mathrm{mg}$ & Promethazine & 1 & $25 \mathrm{mg}$ \\
\hline Diazepam & 2 & $2.5 \mathrm{mg}$ & Ranitidine & 1 & $150 \mathrm{mg}$ \\
\hline Dicyclomine & 1 & $80 \mathrm{mg}$ & Scopolamine & 2 & $1.5 \mathrm{mg}$ \\
\hline Dimenhydrinate & 1 & $100 \mathrm{mg}$ & Solifenacine & 1 & $5 \mathrm{mg}$ \\
\hline Diphenhydramine & 1 & $50 \mathrm{mg}$ & Tapentadol & 1 & $100 \mathrm{mg}$ \\
\hline Doxepine & 2 & $10 \mathrm{mg}$ & Temazepam & 1 & $7.5 \mathrm{mg}$ \\
\hline Doxylamine & 1 & $25 \mathrm{mg}$ & Thiothixene & 1 & $2 \mathrm{mg}$ \\
\hline Duloxetine & 1 & $20 \mathrm{mg}$ & Tizanidine & 1 & $4 \mathrm{mg}$ \\
\hline Escitalopram & 1 & $10 \mathrm{mg}$ & Tolterodine & 1 & $2 \mathrm{mg}$ \\
\hline Fentanyl patch & 1 & $12 \mathrm{mcg} / \mathrm{hr}$ & Tramadol & 1 & $50 \mathrm{mg}$ \\
\hline Fesoterodine & 1 & $4 \mathrm{mg}$ & Tranylcypromine & 1 & $30 \mathrm{mg}$ \\
\hline Flavoxate & 1 & $300 \mathrm{mg}$ & Trazodone & 1 & $25 \mathrm{mg}$ \\
\hline Fluoxetine & 1 & $20 \mathrm{mg}$ & Triazolam & 1 & $0.125 \mathrm{mg}$ \\
\hline Fluphenazine & 1 & $1 \mathrm{mg}$ & Trifluoperazine & 1 & $0.5 \mathrm{mg}$ \\
\hline Flurazepam & 2 & $15 \mathrm{mg}$ & Trihexyphenidyl & 2 & $1 \mathrm{mg}$ \\
\hline Fluvoxamine & 1 & $50 \mathrm{mg}$ & Trimeprazine & 1 & $5 \mathrm{mg}$ \\
\hline Gabapentin & 1 & $300 \mathrm{mg}$ & Trimipramine & 2 & $50 \mathrm{mg}$ \\
\hline Hydrocodone & 1 & $10 \mathrm{mg}$ & Trospium & 1 & $20 \mathrm{mg}$ \\
\hline Hydromorphone & 1 & $4 \mathrm{mg}$ & Zolpidem & 1 & $5 \mathrm{mg}$ \\
\hline Hydroxyzine & 1 & $50 \mathrm{mg}$ & Zopiclone & 1 & $3.75 \mathrm{mg}$ \\
\hline Imipramine & 2 & $25 \mathrm{mg}$ & & & \\
\hline
\end{tabular}

[6] Hayes, A.F. and K. Krippendorff, Answering

\section{References}

[1] Ahmed, S., B. Leurent, and E.L. Sampson, Risk factors for incident delirium among older people in acute hospital medical units: a systematic review and meta-analysis. Age Ageing, 2014. 43(3): p. 326-33.

[2] Siddiqi, N., A.O. House, and J.D. Holmes, Occurrence and outcome of delirium in medical in-patients: a systematic literature review. Age \& Ageing, 2006. 35(4): p. 35064.

[3] Fong, T.G., S.R. Tulebaev, and S.K. Inouye, Delirium in elderly adults: diagnosis, prevention and treatment. Nature Reviews Neurology, 2009. 5(4): p. 210-20.

[4] Inouye, S.K., R.G. Westendorp, and J.S. Saczynski, Delirium in elderly people. Lancet, 2014. 383(9920): p. 911-22.

[5] Semla, T.P., Geriatric dosage handbook: including monitoring, clinical recommendations, and OBRA guidelines. 2013, Lexi-Comp: Hudson, Ohio. the Call for a Standard Reliability Measure for Coding Data. Communication Methods and Measures, 2007. 1(1): p. 77-89.

[7] Campbell, N., et al., Association between prescribing of anticholinergic medications and incident delirium: a cohort study. Journal of the American Geriatrics Society, 2011. 59 Suppl 2: p. S277-81.

[8] Wolters, A.E., et al., Anticholinergic Medication Use and Transition to Delirium in Critically Ill Patients: A Prospective Cohort Study. Critical Care Medicine, 2015. 43(9): p. 1846-52.

[9] Han, L., et al., Use of medications with anticholinergic effect predicts clinical severity of delirium symptoms in older medical inpatients. Arch Intern Med, 2001. 161(8): p. 1099-105.

[10] Carnahan, R.M., et al., The Anticholinergic Drug Scale as a measure of drug-related anticholinergic burden: associations with 
serum anticholinergic activity. Journal of Clinical Pharmacology, 2006. 46(12): p. 14816.

[11] Rudolph, J.L., et al., The anticholinergic risk scale and anticholinergic adverse effects in older persons. Archives of Internal Medicine, 2008. 168(5): p. 508-13.

[12] Boustani, M., et al., Impact of anticholinergics on the aging brain: A review and practical application. Aging Health, 2008. 4(3): p. 311320.

[13] Hilmer, S.N., et al., A drug burden index to define the functional burden of medications in older people. Arch Intern Med, 2007. 167(8): p. 781-7.

[14] Campbell, N., et al., Association between prescribing of anticholinergic medications and incident delirium: A cohort study. Journal of the American Geriatrics Society, 2011. 59(SUPPL. 2): p. S277-S281.

[15] Campbell, N., et al., Association of anticholinergic medications with incident delirium: A cohort study. Journal of the American Geriatrics Society, 2011. 59: p. S128-S129.

[16] Trzepacz, P.T., DELIRIUM: Advances in Diagnosis, Pathophysiology, and Treatment. Psychiatric Clinics of North America, 1996. 19(3): p. 429-448.

[17] Maldonado, J.R., Neuropathogenesis of Delirium: Review of Current Etiologic Theories and Common Pathways. The American Journal of Geriatric Psychiatry, 2013. 21(12): p. 1190-1222.

[18] Viera, A.J. and J.M. Garrett, Understanding interobserver agreement: the kappa statistic. Fam Med, 2005. 37(5): p. 360-3.

\section{Appendix 1 - Search Strategy}

\section{Medline via Ovid Interface}

1. exp Cholinergic Antagonists

2. exp Pharmaceutical Preparations/

3. exp Muscarinic Antagonists/

4."Aged, 80 and over"/ or Aged/

5. Elderly.mp.

6. Old.mp.

7. Late life.mp.

8. Older.mp.
9. Delirium/

10. Confusion/

11. Acuteconfessional state.mp.

12. Disorientation.mp.

13. 1 or 2 or 3

14. 4 or 5 or 6 or 7 or 8

15.9 or 10 or 11 or 12

1613 and 14 and 15

7. Older.mp.

8. Delirium/

9. Confusion/

10. Acute confusion/

12. Disorientation/

13. 1 or 2 or 3

14. 4 or 5 or 6 or 7

15. 8 or 9 or 10 or 11

1612 and 13 and 14

\section{Embase via Ovid Interface}

1. Cholinergic receptor blocking agent/

2. Drug/

3. Muscarinic receptor blocking agent /

4."aged/

5. Old.mp.

6. Late life.mp.

7. Older.mp.

8. Delirium/

9. Confusion/

10. Acute confusion/

11. Disorientation/

12. 1 or 2 or 3

13. 4 or 5 or 6 or 7

14. 8 or 9 or 10 or 11

15. 12 and 13 and 14

\section{Medline via PubMed Interface}

("Cholinergic Antagonists"[Mesh] OR "Cholinergic Antagonists" [Pharmacological Action] OR "Pharmaceutical Preparations"[Mesh]) AND ("Aged"[Mesh] OR "Aged, 80 and over"[Mesh] OR "Frail Elderly"[Mesh]) AND ("Delirium"[Mesh] OR "Confusion"[Mesh] OR acute confessional state OR disorientation) 